\title{
WATERSHED EVAPOTRANSPIRATION INCREASED DUE TO CHANGES IN VEGETATION COMPOSITION AND STRUCTURE UNDER A SUBTROPICAL CLIMATE ${ }^{1}$
}

\author{
Ge Sun, Changqing Zuo, Shiyu Liu, Mingliang Liu, Steven G. McNulty, and James M. Vose ${ }^{2}$
}

\begin{abstract}
Natural forests in southern China have been severely logged due to high human demand for timber, food, and fuels during the past century, but are recovering in the past decade. The objective of this study was to investigate how vegetation cover changes in composition and structure affected the water budgets of a $9.6-\mathrm{km}^{2}$ Dakeng watershed located in a humid subtropical mountainous region in southern China. We analyzed 27 years (i.e., 1967-1993) of streamflow and climate data and associated vegetation cover change in the watershed. Land use/land cover census and Normalized Difference of Vegetation Index (NDVI) data derived from remote sensing were used to construct historic land cover change patterns. We found that over the period of record, annual streamflow $(Q)$ and runoff/precipitation ratio did not change significantly, nor did the climatic variables, including air temperature, Hamon's potential evapotranspiration (ET), pan evaporation, sunshine hours, and radiation. However, annual ET estimated as the differences between $P$ and $Q$ showed a statistically significant increasing trend. Overall, the NDVI of the watershed had a significant increasing trend in the peak spring growing season. This study concluded that watershed ecosystem ET increased as the vegetation cover shifted from low stock forests to shrub and grasslands that had higher ET rates. A conceptual model was developed for the study watershed to describe the vegetation cover-streamflow relationships during a 50-year time frame. This paper highlighted the importance of eco-physiologically based studies in understanding transitory, nonstationary effects of deforestation or forestation on watershed water balances.
\end{abstract}

(KEY TERMS: evapotranspiration; forest hydrology; Normalized Difference of Vegetation Index; Southern China; streamflow.)

Sun, Ge, Changqing Zuo, Shiyu Liu, Mingliang Liu, Steven G. McNulty, and James M. Vose, 2008. Watershed Evapotranspiration Increased Due to Changes in Vegetation Composition and Structure Under a Subtropical Climate. Journal of the American Water Resources Association (JAWRA) 44(5):1164-1175. DOI: 10.1111/j.17521688.2008.00241.x

\footnotetext{
${ }^{1}$ Paper No. JAWRA-07-0113-P of the Journal of the American Water Resources Association (JAWRA). Received August 18, 2007; accepted May 30, 2008. (C) 2008 American Water Resources Association. No claim to original U.S. government works. Discussions are open until April 1, 2009.

${ }^{2}$ Respectively, Research Hydrologist (Sun) and Research Ecologist (McNulty), Southern Global Change Program, USDA Forest Service, Raleigh, North Carolina 27606; Professor and Director (Zuo), Jiangxi Academy of Hydraulic Sciences, Beijing East Rd., Nanchang, China; Associate Professor (S. Liu), College of Land Resources and Environment, Jiangxi Agricultural University, Nanchang, China; Research Fellow (M. Liu), Auburn University, School of Forestry and Wildlife Sciences, Auburn University, Auburn, AL 36849, USA; and Research Ecologist and Project Leader (Vose), Coweeta Hydrologic Laboratory, USDA Forest Service, Otto, North Carolina 28763 (E-Mail/Sun: Ge_Sun@ncsu.edu).
} 


\section{INTRODUCTION}

As the demand for clean water, carbon sequestration, and other watershed ecosystem services intensifies worldwide, it has become increasingly important to understand the role of vegetation cover in regulating the hydrologic cycles at multiple temporal and spatial scales (Jackson et al., 2005; Donohue et al., 2007). The general relationships between vegetation management and streamflow response have been reviewed in a few global syntheses (Zhang et al., 2001; Robinson et al., 2003; Andreassian, 2004; Scott et al., 2004; Ice and Stednick, 2004; Farley et al., 2005; Jackson et al., 2005). These studies suggest that deforestation generally increases water yield and base flow, while reforestation and afforestation reduce those two variables for most watersheds as a result of changes in total evapotranspiration (ET). In humid regions, such as the southeastern United States (U.S.), it is generally accepted that streamflow increases after cutting due to reduced leaf area, but this streamflow response diminishes as leaves recover due to natural succession or growth of planted trees, and streamflow stabilizes with the attainment of canopy (Swank et al., 2001). Changes in species composition can influence how fast streamflow stabilizes and streamflow quantity at canopy closure (Swank et al., 1988). World-wide watershed water-balance data for small watersheds suggest that average annual ET is closely related to precipitation $(P)$, PET, and vegetation water use characteristics (Zhang et al., 2001; Zhou et al., 2002). Similarly, Farley et al. (2005) found that ET increased with an increase in plantation age and leaf area. They confirmed the earlier findings by Bosch and Hewlett (1982) that forests use more water than shrubs and grasses in general.

However, hydrologic response to disturbance is highly nonlinear and variable, and is often influenced by many abiotic and biotic factors including climate, soils, vegetation characteristics (age, leaf area, stomata or stem conductance), and management practices. Without recognizing the high variability, one may have conflicting conclusions and misconceptions on how forest management impacts the temporal dynamics of water yield for any given forest. Other factors such as climate, soils, vegetation characteristics (age, leaf area, stomata or stem conductance), and management practices can influence the magnitude and duration of response. For example, reported increase in water yield response to forest clearcut ranged from none to as high as $800 \mathrm{~mm} /$ year (Bosch and Hewlett, 1982; Andreassian, 2004). The loss of forest cover does not necessarily translate into a long-term increase in watershed water yield. For example, when a forest comprised of Mountain Ash
(Eucalyptus regans) was destroyed by wildfires in Australia, streamflow initially (1-2 years) increased. However, streamflow decreased by $300-400 \mathrm{~mm} /$ year below prefire flow levels due to an increase in transpiration from the emerging vegetation (Kuczera, 1987). In another example found at the Coweeta Hydrologic Laboratory in western North Carolina, Hibbert (1966) reported that the conversion of $80 \%$ of a native deciduous, low tree density hardwoods to Kentucky 31 fescue grass (Fedtuca L.) did not cause an immediate increase in water yield at Coweeta Watershed 6. In fact, the fertilized, highly vigorous, and productive grass system ( $>1 \mathrm{~m}$ in height) used as much water as a native forest (Hibbert, 1966). As grasses died, total annual water yield and base flow increased, especially during the winter seasons. Flow frequency analysis suggested that dense grass or recolonizing forests might use more water than natural mature hardwoods during the summer growing season (Burt and Swank, 1992). A rare long-term study by Scott et al. (2006) suggested that the water yield decreasing trend from an afforested watershed could return to preafforestation after eucalypts or pine plantations matured by the age of 15 and 30, respectively.

More research is needed to better understand the impacts of changing vegetation, composition, and structure on seasonal distribution of streamflow and to address the nonstationarity of forest cover impacts (Andreassian, 2004; Brown et al., 2005). First, comparing to studying the impact studies of deforestation, uncertainties remain regarding the long-term impacts of afforestation on hydrology that depends on the recovery processes of soil, climate, and site productivity (Andreassian, 2004; Bruijnzeel, 2004; Scott et al., 2004, 2006). Sun et al. (2007) offered a conceptual model describing diverse hydrological impacts over time and space for China. Second, most of the "paired watershed" experiments were conducted on small watersheds $\left(<10 \mathrm{~km}^{2}\right)$ and were designed to examine the immediate impacts of forest management (e.g., clearcut harvesting) often with low disturbances on forest soils. Few studies have examined changes in forest structure and composition, and associated ecophysiologic changes on watershed hydrology (Vertessy et al., 2001). Often such kinds of study are troublesome because changes in water yield are difficult to detect with small changes in forest cover (Trimble et al., 1987). Studies that use the "single watershed" approach to compare "before" and "after" water yield are often hampered by incomplete historical records of vegetation cover or climatic variations that confound hydrologic response patterns. It is common that no detailed data are available on vegetation structure and composition for routinely monitored watersheds. This makes the "single watershed" 
based analysis rather difficult when one tries to tie measured flow change to vegetation changes.

Over the past century, forest resources in southern China have been under extreme pressure due to high demands for timber, fuel, and food. Most of the remaining forests are either located in remote areas, or have been cut several times, and are currently in young age classes growing on degraded soils (Fang et al., 2001). The government started implementing measures to restore the existing marginal forests to maximize their ecohydrological functions in "water conservancy," suggesting that the objective was to "moderate floods and augment base flow" (Sun et al., 2007). In some cases, exotic tree species were introduced to achieve both timber production and ecological objectives (Zhou et al., 2002). However, no rigorous long-term "paired watershed" studies have ever been conducted in China that could provide the scientific evidence for the perceived ecological benefits. Empirical observations and data on the positive influences of forests in China on mitigating flooding and drought are limited, often inconclusive, and even contradictory (Wei et al., 2005). Reforestation and soil conservation practices result in decreased streamflow, especially in the Loess Plateau region, and other water-limited environment (Huang and Zhang, 2004; McVicar et al., 2007; Sun et al., 2007). However, limited watershed experimental data also suggested that basins covered by natural virgin forests had higher streamflow than deforested watersheds in the humid south, an energy-limited environment ( $\mathrm{Ma}, 1987$ ). One speculation was that ET from deforested lands increased as evidenced by the higher air temperature in the cut watershed (Huang and Yang, 1987). This short-term watershed study and other retrospective studies based on the "single watershed" method in the headwaters of Yangtze River basins have caused significant confusion among Chinese forest hydrologists and policy makers on the effects of forests on streamflow across China (Wei et al., 2005). Wei et al. (this issue) also questioned the accuracy of the interpretation of observation results in Ma's (1987) "paired watershed" study that lacked a calibration period and detailed process data.

Controversy still remains today on the effects of vegetation change on watershed water yield for different geographic regions in China. It is unclear whether physiographic conditions in southern China are so different from published studies in other parts of the world that results do not apply to China, as is often argued by Chinese forest hydrologists (for more discussion see Wei et al., this issue).

Although limited "paired watershed" studies are rare in China, long-term monitoring hydrometeorological data are available that have the potential to be used for exploring the hydrologic effects of vegetation cover change or/and climate change and variability. In this study, we used one of the few monitored small forest watersheds, Dakeng, to investigate the effects of vegetation cover change on annual streamflow and ET under a humid subtropical climate condition. A preliminary study was reported in mid-1980s (Zhang et al., 1986), but this study represents an in-depth analysis of the long-term data (1967-1993) for the period when the watershed underwent a continuous change in vegetation covers.

We hypothesized that water yield increased and ET decreased at Dakeng watershed, as the forest stocks decreased and shrub and grasslands expanded due to continuous tree logging during 1967-1993. This hypothesis was proposed based on a general rule of existing forest hydrological literature.

The specific objectives were (1) to quantify changes in annual streamflow and ET for the Dakeng Watershed during 1967-1993 and (2) to examine the climatic and vegetation factors affecting the observed hydrologic changes identified in Objective 1. Our ultimate goal was to provide a new insight into the dynamic forest cover-water use-streamflow relationships using long-term data collected from hydrologic monitoring at a humid subtropical watershed. Our key assumption and rationale in determining the drivers for hydrologic changes is that watershed actual ET is controlled by precipitation, PET, and vegetation ET characteristics (e.g., leaf area, transpiration rate per leaf area, species composition, tree age, and canopy interception capacity).

\section{METHODS}

\section{Location and Climatic Characteristics}

The 9.55- $\mathrm{km}^{2}$ Dakeng Watershed (E114 $34^{\prime}$, N29 ${ }^{\circ} 4^{\prime}$ ) is located in northwestern Jiangxi Province, south central China (Figure 1). The second-order stream of Dakeng watershed drains into Xiushui River, one of the five major rivers of Poyang Lake Basin in Jiangxi Province. Poyang Lake has important flood prevention functions for the Yangtze River, but has shrunk in recent decades due to reduction in water flow inputs from its major drainages. Dakeng Watershed drains into two small perennial creeks, and it has an elevation ranging from $117 \mathrm{~m}$ at the outlet to $592 \mathrm{~m}$ at the mountain peak (Figure 1). The mountainous region is dominated by a subtropical eastward and southward monsoon climate characterized by short rainy springs and hot dry autumns and rainy hot summers. The annual average air temperature was $16.5^{\circ} \mathrm{C}$, and has a total rainfall of $1,530 \mathrm{~mm}$ 


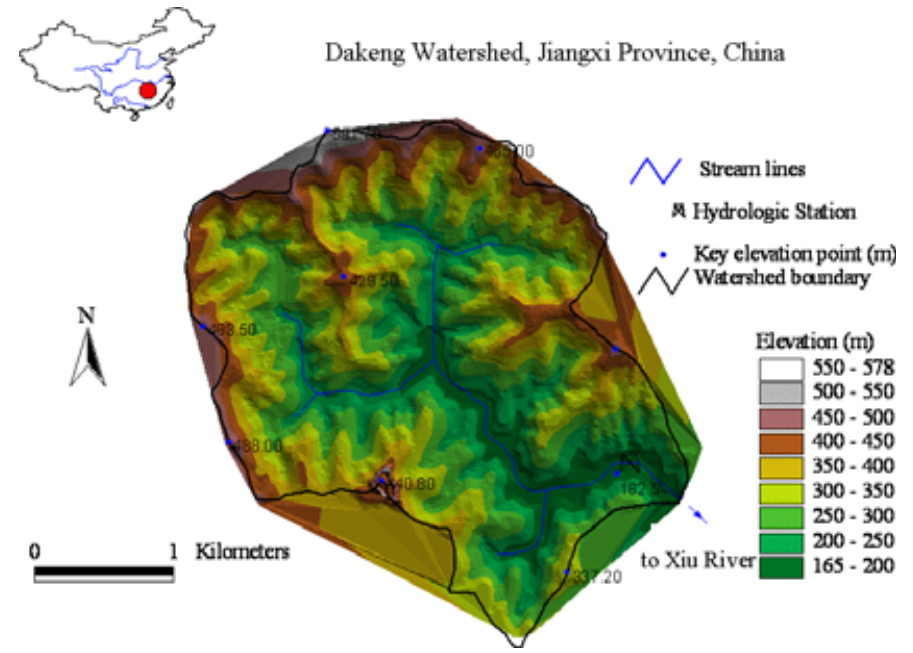

FIGURE 1. Location, Topography, and Instrumentations Layout for Dakeng Watershed.

with about half falling between April and June. The averaged relative humidity was about $80 \%$ and wind speed was generally between 1.5 and $3.0 \mathrm{~m} / \mathrm{s}$.

\section{Land Use, Forest Cover Dynamics Between 1967 and 1993}

The watershed was relatively isolated and remained rather rural with limited road access until the late 1980s. Ground vegetation covers were rather good and little soil erosion occurred as evidenced by the low sediment (clean stream water) in streamflow during storm events. A summary of forest cover changes over the study period is listed in Table 1 to guide the description of sequences of forest cover changes during the study period. We call for caution about the accuracy of the specific statistics. The first two land use surveys were based purely on visual inspection and we suspect that large errors might exist, especially regarding the changes in vegetation composition (i.e., \% of shrubland) over time. Local forest records indicate that before 1960, at least $90 \%$ of the watershed was forested with trees having a diameter at $1.5 \mathrm{~m}$ above ground of $30 \mathrm{~cm}$ or more (Z. Zhang, unpublished data). Intensive logging activities were reported in the $1960 \mathrm{~s}$ and into the late 1970 s, but ended when the land began being administered by a local reforestation agency. The 1978 forest survey suggested that across the watershed, forest lands managed for timber production covered about $66 \%$ of the area, shrublands and other type of forests managed for household incomes covered $19 \%$ of the watershed, and the other $15 \%$ of the area was considered as croplands. Deforestation activities were curbed somewhat and forest recovery began in the mid-1980s. A 1986 survey showed that timber lands and shrub/grasslands represented 62 and $25 \%$ of the basin area, respectively. The remaining forests were poorly stocked with approximately $30 \mathrm{~m}^{3} /$ ha. Most trees had a height less than $12 \mathrm{~m}$ and diameter at breast height (DBH) of less than $15 \mathrm{~cm}$ (Zhang et al., 1986, unpublished report). Interviews with local residents indicated that the over-harvesting activities started to accelerate again in the late 1980s when the reforestation agency left and the forest lands were given back to the local residences in the watersheds. In lieu of field data for the 1990s, we used TM imagery (30 m resolution) for 1992 to give a rough estimate of forest cover conditions. Remote sensing data suggested that forests and shrublands covered about $71 \%$ and $20 \%$ of the watershed, respectively, with the rest classified as water body and croplands. The remote sensing data might have overestimated the forest coverage and underestimated the shrubland areas. Considerable uncertainty exists with the TMbased landcover classification because we were unable to ground truth ground cover classifications. Also, both the field survey and remote sensing data do not provide information about the quality (species composition, tree density, leaf area) of the lands classified as forests. Based on previous studies (Zhang et al., 1986; Sun and Zhang, 1989) and field observations, it is safe to say that the number of large trees

TABLE 1. Estimated Chronological Sequences of Land Cover and Land Use for Dakeng Watershed During 1967-1993.

\begin{tabular}{|c|c|c|c|}
\hline Time Period & Land Cover Characteristics & Land Use Objectives & References \\
\hline Late $1960 \mathrm{~s}$ & Mostly native forests $90 \%$ forests & Self-sufficient rural economy & Based on interview with locals \\
\hline 1970s & $\begin{array}{l}\text { Logging native forests; } 66 \% \text { forest, } \\
\text { shrubs } 19 \% \text {, crop lands } 15 \%\end{array}$ & Managed for timber production & Zhang et al., 1986 \\
\hline $1980 \mathrm{~s}$ & $\begin{array}{l}\text { Limited logging, some reforestation; } \\
62 \% \text { of forests, } 25 \% \text { of shrub/grass- } \\
\text { lands; } 13 \% \text { of croplands }\end{array}$ & $\begin{array}{l}\text { Forest protection enforced } \\
\text { before mid-1980s; logging } \\
\text { increased somewhat after } \\
\text { mid-1980s; low timber stock }\end{array}$ & $\begin{array}{l}\text { Based on site visit; } \\
\text { Zhang et al., } 1986\end{array}$ \\
\hline Early 1990s & $\begin{array}{l}\text { Somewhat forest recovery } 71 \% \\
\text { forests, } 20 \% \text { shrubs, crop lands } 9 \% \text {. }\end{array}$ & $\begin{array}{l}\text { Reduced land pressure for crop } \\
\text { production due to external } \\
\text { increase of income }\end{array}$ & $\begin{array}{l}\text { Remote sensing analysis } \\
\text { derived from uncalibrated } \\
\text { TM imagery }\end{array}$ \\
\hline
\end{tabular}


and forest stocks in the watershed have been declining over the study period. It is likely that the number of smaller trees, and sprouts from the cut-over stands have increased, and shrubs and grasslands have increasingly dominated the vegetation composition at the watershed scale.

To reduce the uncertainty on the land cover compositions of the watershed, we also acquired remote sensing data to study the change in vegetation structure (i.e., leaf area). Vegetation Normalized Difference of Vegetation Index (NDVI) is an important index of vegetation cover "greenness" characteristics and generally correlates positively with water loss through ecosystem ET (Szilagyi, 2000). Therefore, in addition to acquiring forest survey records, we also extracted watershed NDVI as a proxy of leaf area to examine the trend ET capacity over the study period. We acquired two types of remote sensing products to detect landcover change over time. One type of data with a high resolution was from the Global Land Cover Facility (GLCF) (http://glcf.umiacs.umd.edu/index. shtml; ftp://ftp.glcf.umiacs.umd.edu/glcf/Landsat/). All the images have been orthorectified and the absolute positional accuracy for MSS is $100 \mathrm{~m}$ and for TM/ETM is $50 \mathrm{~m}$. The original spatial resolution is 57.0 and $28.5 \mathrm{~m}$ for MSS and TM/ETM, respectively. The date for the MSS and TM images is November 6, 1979 and October 18, 1992, respectively. The other type of data, bimonthly AVHRR 8-km NDVI between 1981 and 1993, was acquired from the Global Inventory Modeling and Mapping Studies (GIMMS) datasets. The datasets have been corrected for calibration, view geometry, volcanic aerosols, and other effects not related to vegetation change (Tucker et al., 2005).

As a result of logging beginning in the 1960s and subsequent reforestation for timber production in the late $1980 \mathrm{~s}$, the original evergreen deciduous forests dominated by Liguidambar formasana and Cyclobalanopsis glauca have been replaced by Chinese fir (Cunninghamia lancelata) and Masson pine (Pinus massoniana) (called horsetail pine locally). Both tree species were widely planted throughout southeastern China. The understory species for timber land forests and shrublands were dominated by the woody shrub species, Loropetalum Chinese, and the herbaceous grass, Disranopteris dichotoma, and many other fastgrowing subtropical plants. When the coniferous trees were cut, the shrubs and grasses grew rapidly under the humid subtropical climatic conditions.

\section{Hydrometeorological Databases}

Streamflow data were collected between 1966 and 1993 at Dakeng Hydrologic Station, one of the hydrologic monitoring station networks of Jiangxi Province.
Hydrologic monitoring of such a small watershed for such a long-time period with a high standard is rare in China. A composite concrete flume with an $\mathrm{H}$-shape bottom and a V-shape for the two wings accommodates both high and low flows. Water level fluctuations were continuously recorded on a Steven-F type water level recorder with a 15-minute resolution. Little erosion and sediment loading occurred in this watershed as visually observed in the clear streamflow even during storm events. Daily precipitation, air temperature, relative humidity, sunshine hour, and pan evaporation data were acquired from a standard weather station located about $20 \mathrm{~km}$ from the watershed. In lieu of measured radiation data at the weather station, we generated the monthly radiation time series for this watershed by interpolating the coarse global radiation data (280-km resolution) with bilinear method, i.e., weighted average determined by the value of the four nearest global cell centers. The global ISCCP-FD RadFlux dataset (Zhang et al., 2004) was developed from a new radiative transfer model and new remote sensing datasets (ISCCP-D1) that took account of atmospheric and surface properties as well as cloud properties.

Potential ET represents the maximum water loss for a given watershed with no soil water stress. In humid regions, actual ET is closely related to PET under forested conditions ( $\mathrm{Lu}$ et al., 2005). We used a temperature-based PET method to calculate daily PET for the study watershed. The Hamon's method has been widely used in humid eastern U.S. and reported to provide reasonable PET for forested conditions (Vörösmarty et al., 1998; Sun et al., 2002; Lu et al., 2005; Sun et al., 2005). This method uses temperature as the major driving force for ET, but also includes other variables such as daytime length and saturated vapor pressure calculated based on air temperature.

$$
\mathrm{PET}=0.1651 \times \mathrm{DAYL} \times \mathrm{RHOSAT} \times \mathrm{KPEC},
$$

where PET is the forest potential ET ( $\mathrm{mm} /$ day); DAYL is the time from sunrise to sunset in multiples of $12 \mathrm{~h}$, calculated from date, latitude, slope, and aspect of the watershed; and RHOSAT is the saturated vapor density $\left(\mathrm{g} / \mathrm{m}^{3}\right)$ at the daily mean temperature (TEMP) in ${ }^{\circ} \mathrm{C}$ and is calculated by

$$
\text { RHOSAT }=216.7 \times \frac{\text { ESAT }}{\mathrm{TEMP}+273.3},
$$

where ESAT is the saturated vapor pressure (millibars) and is defined by 


$$
\mathrm{ESAT}=6.108 \exp \left(\frac{17.26939 x \mathrm{TEMP}}{\mathrm{TEMP}+273.3}\right)
$$

KPEC is a correction coefficient to adjust PET calculated using Hamon's method to derive realistic values for forest ecosystems. We used 1.1 for this study based on our application experience in the southeastern U.S. that has a similar climate to southern China (Lu et al., 2005; Sun et al., 2005).

\section{Watershed Water Balances}

ET can be estimated by the watershed water balance equation

$$
\mathrm{ET}=P-Q \pm \Delta S
$$

where, ET, $Q, P$, and $\Delta S$ are evapotranspiration, streamflow, precipitation, and the change in soil water storage, respectively. At an annual time scale, the magnitude of $\Delta S$ is relatively small when compared with ET fluxes that have a magnitude of $900 \mathrm{~mm} /$ year in southern China. For a hilly watershed with low soil water storage capacity, the term $\Delta S$ was likely to be small, and thus we assumed that it was negligible at the annual scale. Therefore, we estimated annual ET as the straight difference between measured $P$ and $Q$.

\section{Trend Analysis and Significance Tests}

Trend analysis by developing linear models relating hydroclimatic variables with time (month or year) and regression statistical tests were conducted using SAS (SAS Institute Inc., 2001). A series of linear regression models were used to examine the interactions of hydrologic and climatic variables. For all trend analyses, we used a significant level of $\alpha=0.05$ to detect change in slopes of the regression models.

\section{RESULTS}

\section{Climatic and Hydrologic Variability and Trend}

Linear regression analysis suggested that annual total sunshine hours, pan evaporation, estimated radiation, and Hamon's PET did not change significantly during the study period (1967-1993), although they all showed downward trends, nor did average air temperature and annual total precipitation, which showed a somewhat upward trend.

Average annual precipitation $(P)$ was $1,548 \mathrm{~mm}$ with the highest amount $(2036 \mathrm{~mm})$ and lowest $(1,011 \mathrm{~mm})$ occurring in 1967 and 1968, respectively (Figure 2). The annual water yield $(Q)$ and runoff coefficient $(Q / P)$ closely followed with the precipitation patterns. Linear regression analysis suggested that precipitation explained $87.2 \%(p<0.0001)$ of the variation of annual runoff. There was no statistically significant relationship between air temperature and annual runoff $(p=0.56)$. On average, about $51 \%$ of the annual precipitation, or $792 \mathrm{~mm}$, ran off as streamflow, and the rest $(756 \mathrm{~mm}$ or $49 \%$ of $P$ ) returned to the atmosphere as ET.

Similar to the trend of climatic variables, annual water yield $(Q)$ and the runoff coefficient $(Q / P)$ did not show a statistical trend, although they showed somewhat downward trends over the study period (Figure 2). A linear regression model with water yield as the dependent variable and precipitation and time (year) as the independent variables suggests that precipitation and time are the two significant influential variables $(p<0.01)$, which together explained $90 \%$ of the variability of water yield. Now the question is what caused the decreasing trend in water yield that could not be explained by PET or air temperature that did not show a detectable change.

Surprisingly, annual ET estimated as the difference of $P$ and $Q$ showed a significant increase over time $(p=0.014)$ at a rate of $62 \mathrm{~mm}$ per decade (Figure 3). Linear regression analysis found that neither precipitation nor air temperature could explain the variability of $\mathrm{ET}(p>0.07)$. In multiple regression analyses, annual precipitation, average air temperature, and PET explained only $22 \%$ of the variation in

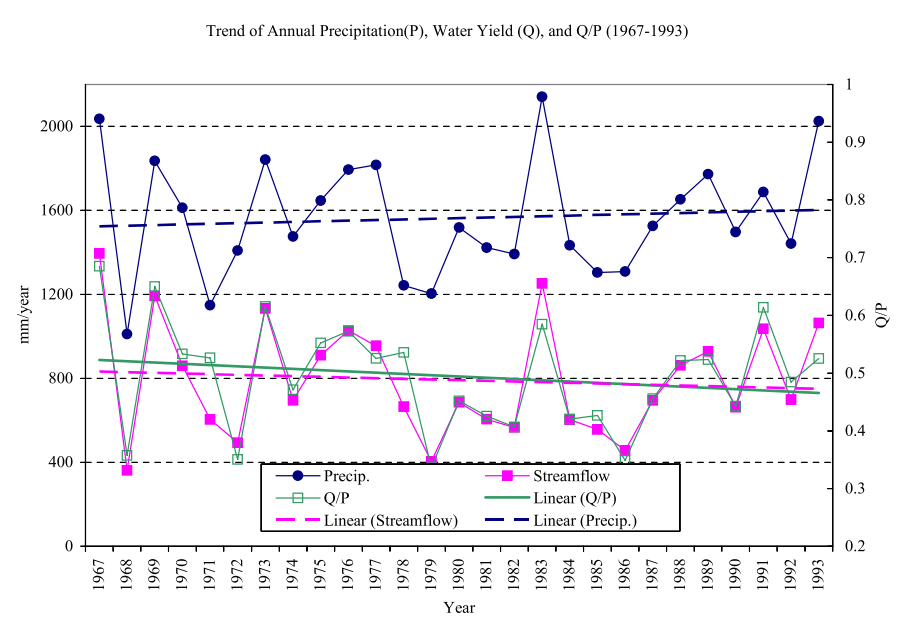

FIGURE 2. Upward Trend for Annual Precipitation $(P)$, but Downward Trend for Streamflow $(Q)$ and Q/P Ratio During the Study Period, 1967-1993. Trends were not significant statistically $(p>0.3)$ for all three variables. 
Trend of Annual ET (caculated as P - Q) (1967-1993)

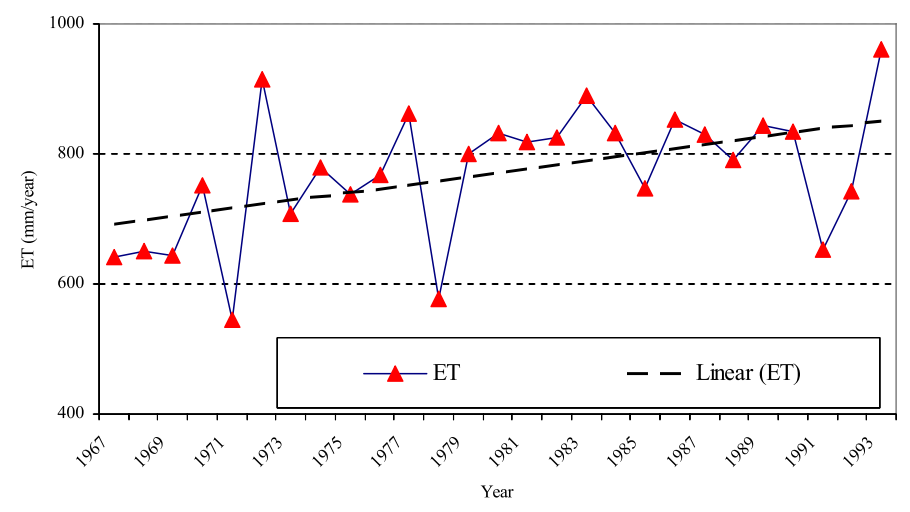

FIGURE 3. Annual Evapotranspiration Calculated as $P-Q$ Had a Significant Trend $(p<0.02)$ During the Study Period, 1967-1993.

annual ET, suggesting that other factors such as vegetation cover may have played a role in regulating the increase of ET over the study period.

We also conducted a similar trend analysis for the climatic and water yield variables of the growing season (April-September). The general findings at the annual scale applied to the entire growing season (April-September) and the peak growing season (June and July) that received the highest rainfall and energy input (Figure 4).

\section{Monthly Distributions of Hydrologic Variables}

Both precipitation and runoff were unevenly distributed within a year and skewed toward the first

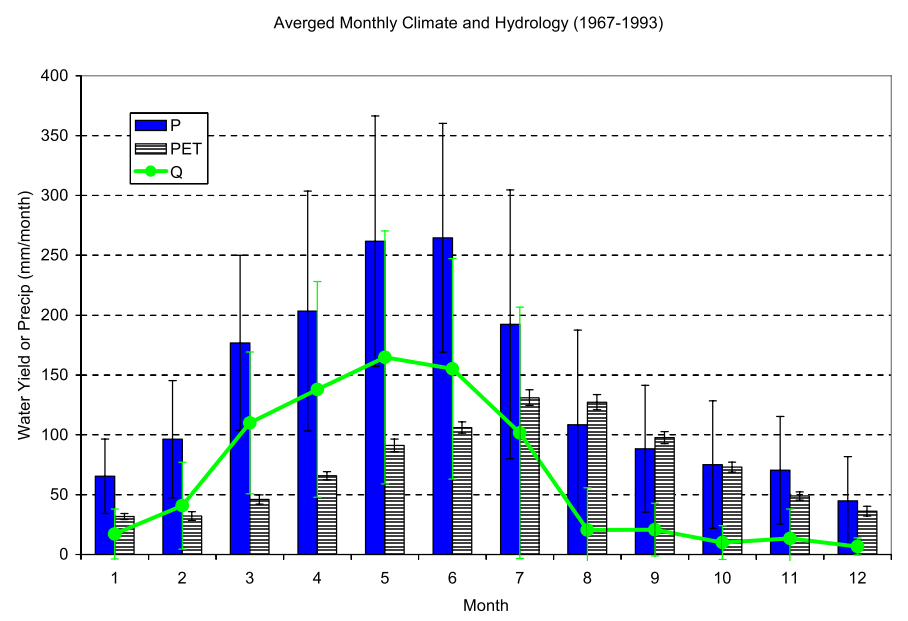

FIGURE 4. Monthly Distributions of Averaged Precipitation, Water Yield, Hamon's Potential ET, Show That Water Yield Concentrated Around March-June and Followed Closely With Precipitation Pattern. The error bars show one standard deviation of monthly values. half of the year (Figure 4). Monthly streamflow dropped sharply in July and remained low until February with a sum of only $27 \%$ of the annual total. Low rainfall and high ET demand resulted in low flows during the late summer and the fall months. Precipitation was almost balanced by ET during August-December resulting in a long low-flows period. Less than $20 \%$ of rainfall became streamflow between August and January, compared with the annual average $Q / P$ ratio of $51 \%$ and the rainy season (March-June) of $63 \%$. Given the precipitation and PET patterns, the peak actual ET season likely fell from May to August (Figure 4).

\section{Changes in NDVI and Radiation Derived From Remote Sensing Data}

Bimonthly AVHRR NDVI data were available only for the 1982-2003 time periods. Annual average and growing season (April-September) NDVI averages had an increasing trend (not statistically significant) during 1982-1993. However, the May-June period showed a much clearer upward trend $(p<0.09)$ (Figure 5). NDVI appeared to reach its peaks earlier and faster during 1987-1993 than during 1982-1986 (Figure 6), perhaps indicating that the watershed had much higher leaf area in the peak-growing season during the second time period than the first time period. The fall months had a much higher NDVI than the spring months as in most ecosystems dominated by conifer forests.

The MSS and TM landcover data with a higher spatial resolution than the AVHRR data suggested that NDVI changed little, from 0.38 on November 6 , 1979 to 0.34 on October 18, 1992. However, the histo-

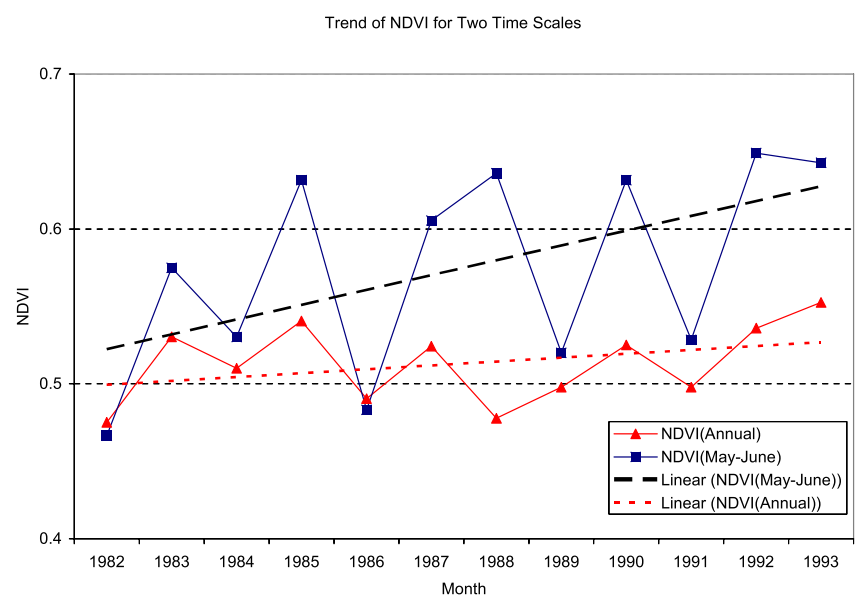

FIGURE 5. NDVI for the Peak Growing Season Increased Significantly $(p=0.09$ ), but Annual Averaged NDVI Did Not Show a Significant Increase During the Study Period, 1982-1993. 


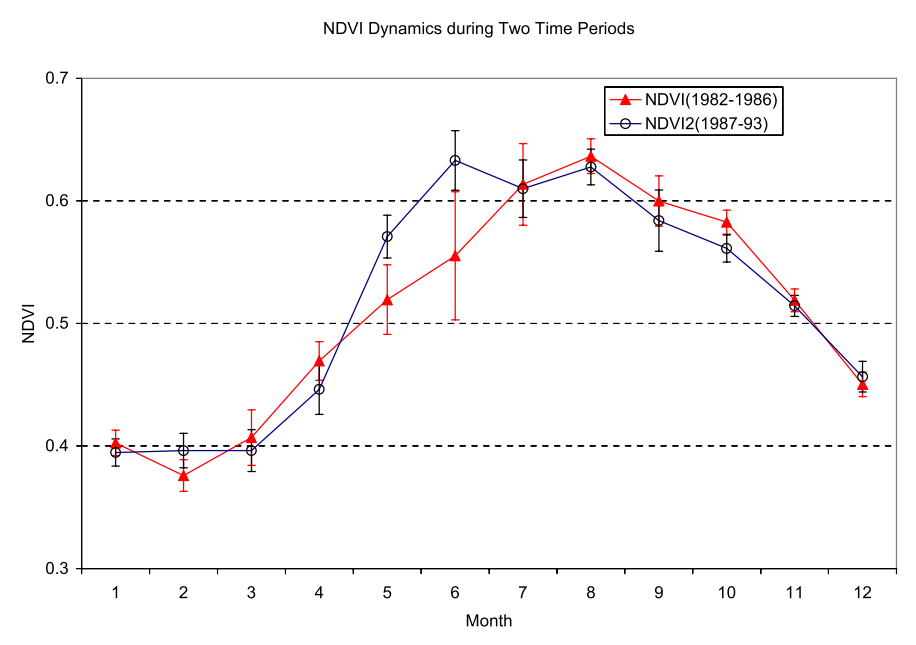

FIGURE 6. Monthly Averaged NDVI Distributions for Two Periods Suggest a Shift of Peak Leaf Area During the Study Period, 19671993. The error bars show standard errors of monthly values.

gram of band distribution showed that the significant number of pixels with higher NDVI values shifted to low values. This shift confirmed that the leaf of area or number of large conifer evergreen trees might have been reduced from 1979 to 1992 . This is consistent to findings presented in Figure 5. Unfortunately, this study was not successful in acquiring remote sensing scenes for the peak summer growing season; thus, we could not provide confirmative evidence that leaf area increased during the growing season. Additional studies are needed in this aspect of the research.

\section{DISCUSSION}

\section{Changes in Water Balances Linked to Progressive Vegetation Succession}

We presented a long-term dataset that included measured hydrometerological variables and associated land cover dynamics. Because the watershed was not designed for the traditional "paired watershed" study, and the vegetation change was characterized as rather continuous, sporadic, and "uncontrolled." This situation made the analysis rather challenging, but this study offered a unique opportunity to examine how changes in forest composition and structure affect streamflow and ET. Most forest hydrology literature that offers definitive answers on the forest-water relationships is based on "controlled" experiments that vegetation changes are either abrupt or unidirectional.
Contrary to our hypothesis that continuous sporadic logging of large trees will increase water yield by reducing ET, our data suggested that annual ET was increasing significantly. As all climatic variables including PET and precipitation and water yield had no significant trend over the study period, we argue that the significant increase in ET in Dakeng Watershed was primarily a result of changes in vegetation characteristics such as leaf area index, sprouting of new trees, increase in plant density, resulting in an increase of total ecosystem water use. The slight increase in $P(30 \mathrm{~mm} /$ decade $)$ might have helped elevating ET somewhat, but it is not likely to be responsible for the large rise in ET $(60 \mathrm{~mm} /$ decade). Therefore, based on hydrologic water balance principles and factors affecting ET, we believe that vegetation changes in composition and structure over the study period were the primary causes for the increase in ET. We argue that if vegetation had remained being stable or shifted to species with comparable LAI and water use rates, then ET would be similar in the two study periods. In the next paragraph, we present hypotheses to link the increase in ET to vegetation change by using published plant physiological data.

\section{Hypotheses to Explain the Increase in Annual Evapotranspiration}

Increase in NDVI or leaf area has been linked to increase in ET in previous studies (Cornish and Vertessy, 2001; Sun et al., this issue). This study found that NDVI displayed an increasing trend during the growing season over the study period. The increase in NDVI was likely a result of shrubland expansion and higher reflectance from the grasses compared with the dark-colored Chinese firs and pines or mixed fir-pine stands.

The discussion above suggests that the watershed covered by large shrubs and grasses might have higher ET than the previous tree-dominated forests. This could be caused by at least two factors: (1) leaf-level transpiration studies in the late 1980s found that the dominant shrub species Loropetalum Chinese had a much higher transpiration rate per unit of leaf mass than the tree species Chinese firs (Cunninghamia lancelata) and Masson pines (Pinus massoniana) they replaced (Figure 7); and (2) average canopy rainfall interception of shrubs was about $21 \%$, comparable to or even higher than forest stands (Zhang et al., 1986). A complete comparison of ET at the stand scale between shrub/ grasslands and a forest stands is not available for the study watershed. However, higher transpiration rates, leaf area, and canopy interception all suggest 
Comaprision of Averaged Plant Transpiration Rates (1985-1986)

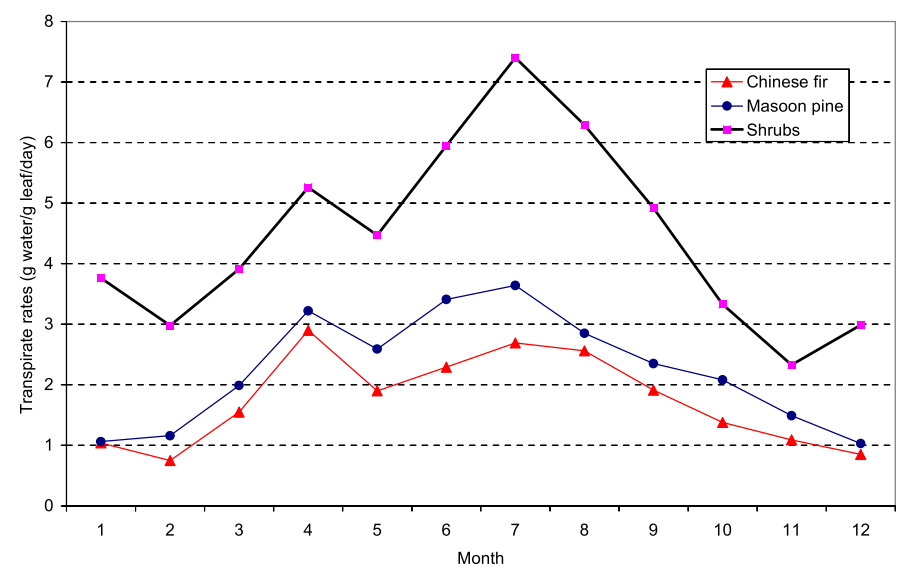

FIGURE 7. Measured Averaged Monthly Transpiration Rates of Chinese Fir (Cunninghamia lancelata), Masson Pine (Pinus massoniana), and a Shrub Community (dominated by Loropetalum Chinese) From 1985 to 1986 (redrawn from Zhang et al., 1986).

that the shrublands have higher ET rates compared with either pine or conifer stands during the growing season. During the fall and winter nongrowing seasons, leaf area of the evergreen needleleaved forest stands and ET rates should be higher than for the shrubs. However, precipitation, air temperature, and transpiration rates were rather low (Figure 4) during these periods, so, large differences in total ET between the two types of ecosystem were not expected. Therefore, an expansion of shrub and grasslands likely caused sharp increase in both annual canopy interception and transpiration rates; however, the sharp increase of ET did not cause a similar decrease in water yield due to the buffering effects of a slight increase in precipitation input.

Our findings are consistent with international literature. Long-term "paired watershed" studies in North America, U.K., and Australia showed that the observed magnitude of water-yield change was a function of duration of forest recovery and changes in physiological characteristics (e.g., leaf area, sap wood area) of disturbed forest ecosystems (Andreassian, 2004). Andreassian (2004) and Brown et al. (2005) suggested that the nonstationary impacts of forest cover change on seasonal water yield are extremely variable. This study provides new data on the hydrologic effects of forest cover change in composition and structure.

Traditional literature (Bosch and Hewlett, 1982; Zhang et al., 2001) and lately the work of Farley et al. (2005) showed that forests have higher ET than shrublands and grasslands. This generalization is for overall description of vegetation-water relationship and should not be used for site-specific applications. Indeed, these syntheses have found a large variability due to variations of vegetation composition and structure, climate, and soil conditions. Our study is a good example to show that the general "rule of thumb" does not apply to local conditions. When plantation forests were degraded and shrubs and grasses expanded due to human interferences or natural recovery, watershed-scale ET could gradually increase at a significant pace. This suggests that shrub and grasslands growing under a humid and warm environment with undisturbed soils could exceed the ET capacity of forests with low stock and productivity. A careful definition of a forest's composition and structure is critical when one evaluates its functions in affecting the hydrological balances. Published forest hydrology literature has been well summarized by the generalized ET model by Zhang et al. (2001). This model showed that forests have a much higher ET than grasslands under a moist environment, and it has been widely used to assess the consequences of landcover change on watershed water yield (Sun et al., 2005, 2007; McVicar et al., 2007). We argue that the empirical plant water use parameter of the Zhang's model reflects vegetation ET capacity and land surface characteristics (Zhang et al., 2001), thus it should not be viewed as a surrogate of landcover type. A simple land classification of "forest" vs. "shrub" or "grass" is not sufficient to define the differences in ecosystem ET rate. In other words, it is the ET capacity, the sum of canopy interception, soil evaporation, and plant transpiration that determine the hydrologic changes, not land cover types. This distinction is especially important in forest hydrological research sites when classic-paired watershed-manipulation experiments are not available or "pairs" are used without calibration. In such cases, a forest stand on degraded soils with low leaf area and productivity may have lower ET than a stand dominated by shrubs or grass with a higher leaf area and productivity.

This study may help partially explain Ma's (1987) "controversial" study discussed earlier that documented that water yield in a deforested watershed was lower than in its "control," an old growth forest in the up reach Yangtze River. As proposed by Huang and Yang (1987), we hypothesized that the ET rates of the newly regenerated vegetation were actually higher than the "control" forest at the time the hydrologic investigation occurred (1966). The reported harvesting treatments were conducted 10 years earlier between 1956 and 1962. It was likely that water yield indeed increased right after clearing the old growth forest in the $1950 \mathrm{~s}$, but decreased to level lower than the "control" 10 years later when the forests regenerated and ET reached a rather high level. 


\section{A Conceptual Model Describing the Forest Cover-Water Balance Relations}

Currently, the Dakeng Watershed is dominated by young forest stands with a low tree density and shrub and grasslands that has decreased human disturbance due to reduction in firewood consumption in the watershed. Based on our data and projected land cover change patterns, we developed a conceptual model that describes qualitatively how the hydrology of the Dakeng watershed has changed and predicts future changes in light of recently observed climatic warming and forest recovery (Figure 8). This conceptual model divides the hydrologic changes into five periods according to the vegetation dynamics as influenced by socioeconomic development during the past 50 years. This study analyzed only Period 3 and Period 4 .

Period 1. Prior to the early 1960 s, the watershed was covered with forests that were composed of large, native tree species (i.e., evergreen broadleaf forests). This period was defined as the baseline of hydrologic conditions characterized as having high ET and low water yield.

Period 2. During the 1960s, intensive logging and the conversion of native forests to plantations dominated by Chinese firs and pines greatly reduced timber stocks. ET may have been reduced and water yield increased greatly from the baseline due to lower leaf area and lower transpiration rates.

Period 3. During the 1970s, large trees were logged but some reforestation occurred with Chinese fir and Masson pine within the watershed. ET increased and water yield started to decrease comparing to Period 2.

Period 4. During the 1980 s, poorly stocked forest plantations (low DBH and tree height) grew back

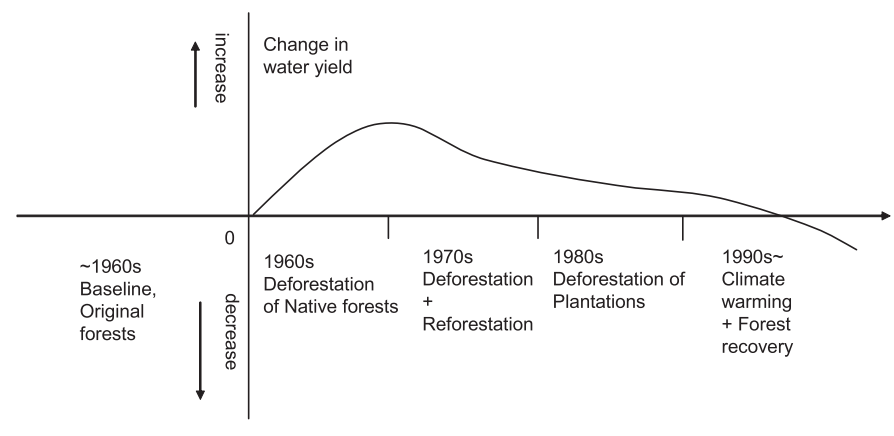

FIGURE 8. A Conceptual Model Describing Water Yield Changes for Dakeng Watershed During the Past 50 Years as a Result of Disturbances by Deforestation, Reforestation, and Climate Change. with low forest productivity, and shrub and grasses covered degraded hillslopes that failed to grow crops. ET increased and water yield decreased because of the vigorous growth of young plantation stands and expansion of shrublands.

Period 5. During the earlier 1990s, more large trees were cut from the plantations, and shrubs and grasslands continued to increase. During the late 1990 s, local air temperature was rising significantly. Precipitation became more variable, especially in the summer months. Actual ET is expected to increase and total annual flow to decrease to a point lower than the baseline (prior to 1960). Flow extremes and variability may increase during the 21st Century due to climate change.

\section{CONCLUSIONS}

This study rejected the initial hypothesis that watershed water yield would increase and ET would decrease when the watershed was under periodic logging and losing trees. Instead, we concluded that total ET loss from Dakeng watershed had increased between 1967 and 1993. The significant increasing trend of ET explained the dynamics of annual and seasonal water yield. We concluded that the change in water balances was a result of vegetative cover changes in composition and structure. Unlike classiccontrolled watershed experiments, the land disturbance in this study did not cause abrupt forest cover changes, and its hydrologic effects were rather subtle, especially when variation in climate over this period of time was considered. Direction of change in water yield in the future will be influenced greatly by climatic change and variability. This study suggests that an eco-physiological approach is needed to fully understand and explain the changes in hydrological balances at a watershed scale. Future studies should focus on quantifying the ET differences between a poorly stocked Chinese fir plantation and a shrub/ grass community.

Existing general models such as those applied to the continual scale (Zhang et al., 2001) offer only general guidance of vegetation-water relationships, and they cannot be applied to specific cases where detailed vegetation parameters are not available. This is also demonstrated by the rather complex nonlinear relationships between reforestation and water yield response in Farley et al.'s (2005) global synthesis. Our study demonstrates the importance of quantifying the changes of vegetation characteristics, and timing of the assessment when reporting the 
hydrologic impacts of deforestation or reforestation. Deforestation can be a dramatic event that reduces biomass to a minimum in a short time period or a gradual process that alters vegetation structure and compositions completely over a much longer period. The former case is common in experimental settings or normal forest management operations (i.e., clearcut), but the latter case is common in certain areas in China where the existing young forests continue to degrade or recover under a changing socioeconomic and natural regimes. The hydrologic impacts of the two scenarios may have different results, although both cases can be reported as "Deforestation" effects. Similarly, in practice, forestation (reforestation or afforestation) can have many choices in tree species and silvicultural operations that profoundly affect the magnitude, timing, and directions of hydrologic impacts. An accurate definition is needed when evaluating the effects of "deforestation" or "forestation" on watershed hydrology. Our study provided an example and a unified rationale that can explain the seemingly contradictory results reported in China and elsewhere.

\section{ACKNOWLEDGMENTS}

This study would not have been possible without the financial support by the Southern Global Change Program, USDA Forest Service, and the Institute of Soil and Water Conservation of Jianxi Province, China. We would like to acknowledge the earlier pioneers who conducted forest hydrological studies in Dakeng Watershed, especially Zengzhe Zhang, Yuxing Yang, Kangning He, Xinxiao Yu from Beijing Forestry University, and Mr. Jinqiu $\mathrm{Hu}$ and Liyi $\mathrm{Lu}$ from Xiushui County, Jiangxi Province.

\section{LITERATURE CITED}

Andreassian, V., 2004. Waters and Forests: From Historical Controversy to Scientific Debate. Journal of Hydrology 291:1-27.

Bosch, J.M. and J.D. Hewlett, 1982. A Review of Catchment Experiments to Determine the Effect of Vegetation Changes on Water Yield and Evapotranspiration. Journal of Hydrology 55:3-23.

Brown, A.E., L. Zhang, and T.A. McMahon, 2005. A Review of Paired Catchment Studies for Determining Changes in Water Yield Resulting From Alterations in Vegetation. Journal of Hydrology, 310:28-61.

Bruijnzeel, L.A., 2004. Hydrological Functions of Tropical Forests: Not Seeing the Soils for the Trees. Agriculture Ecosystems and Environment 104:185-228.

Burt, T.P. and W.T. Swank, 1992. Flow Frequency Responses to Hardwood-to-Grass Conversion and Subsequent Succession. Hydrological Processes 6:179-188.

Cornish, P.M. and R.A. Vertessy, 2001. Forest Age-Induced Changes in Evapotranspiration and Water Yield in a Moist Eucalypt Forest in New South Wales, Australia. Journal of Hydrology 150:301-322.

Donohue, R.J., M.L. Roderick, and T.R. McVicar, 2007. On the Importance of Including Vegetation Dynamics in Budyko's
Hydrological Model. Hydrology and Earth System Sciences 11:983-995.

Fang, J., A. Chen, C. Peng, S. Zhao, and L. Ci, 2001. Changes in Forest Biomass Carbon Storage in China Between 1949 and 1998. Science 292:2320-2322.

Farley, K.A., E.G. Jobbágy, and R.B. Jackson, 2005. Effects of Afforestation on Water Yield: A Global Synthesis With Implications for Policy. Global Change Biology 11(10):1565-1576.

Hibbert, A.R., 1966. Forest Treatment Effect son Water Yield. In: International Symposium on Forest Hydrology. National Science Foundation Adv. Sci. Seminar Proceedings, 1965, W.E. Sopper and H.W. Lull (Editors). Pergamon Press, New York, pp. 527543.

Huang, L. and Y. Yang, 1987. On the Conservation Function of Natural Forest in Western Sichuan. In: Proceedings of a Workshop on Forest Hydrologic Resources in China: An Analytical Assessment. Harbin, China. August 18-23, 1987, P. Ffolliott and D.P. Guertin (Editors). United States Man and Biosphere Program, Springfield, VA, $121 \mathrm{pp}$.

Huang, M. and L. Zhang, 2004. Hydrological Responses to Conservation Practices in a Catchment of the Loess Plateau, China. Hydrological Processes 18:1885-1898.

Ice, G.G. and J.D. Stednick, 2004. A Century of Forest and Wildland Watershed Lessons. Society of American Foresters, Bethesda, Maryland, $287 \mathrm{pp}$.

Jackson, R.B., E.G. Jobbagy, R. Avissar, et al. 2005. Trading Water for Carbon With Biological Carbon Sequestration. Science, 310:1944-1947.

Kuczera, G., 1987. Prediction of Water Yield Reductions Following a Bushfire in ash-Mixed Species Eucalypt Forest. Journal of Hydrology 94:215-236.

Lu, J., G. Sun, D.M. Amatya, and S.G. McNulty, 2005. A Comparison of six Potential Evapotranspiration Methods for Regional use in the Southeastern United States. Journal of American Water Resources Association 41:621-633.

Ma, X., 1987. Hydrologic Processes of a Conifer Forest in the SubAlpine Region in Sichuan, China. Scientia Silvae Sinicae, 23:253-265 [in Chinese].

McVicar, T.R., L.T. Li, T.G. Van Niel, L. Zhang, R. Li, Q.K. Yang, X.P. Zhang, X.M. Mu, Z.M. Wen, W.Z. Liu, Y.A. Zhao, Z.H. Liu, and P. Gao, 2007. Developing a Decision Support Tool for China's re-Vegetation Program: Simulating Regional Impacts of Afforestation on Average Annual Streamflow in the Loess Plateau. Forest Ecology and Management 251:65-81.

Robinson, M., A.L. Cognard-Plancq, C. Cosandey, 2003. Studies of the Impact of Forests on Peak Flows and Baseflows: A European Perspective. Forest Ecology and Management 186: 85-97.

SAS Institute Inc., 2001. SAS User's Guide 8.2. SAS Institute Inc., Cary, North Carolina.

Scott, D.F., L.A. Bruijnzeel, and J. Mackensen, 2004. The Hydrologic and Soil Impacts of Reforestation. In: Forests, Water and People in the Humid Tropics, M. Bonell, and L.A. Bruijnzeel (Editors) Cambridge University Press, Cambridge, U.K., pp 622651.

Scott, D.F., E. Prinsloo, and G. Moses, 2006. The Long-Term Effects of Pine and Eucalypt Plantations on Streamflow, and a Possible Link to Site Productivity. In: Proceedings of the Conference on Forest and Water in A Changing Environment, 8-10 August 2006, Beijing, China, S. Liu, G. Sun, and P. Sun (Editors). Chinese Academy of Forestry, Beijing, pp. 191-193.

Sun, G., S. McNulty, D. Amatya, R. Skaggs, L. Swift, Jr., J. Shepard, and H. Riekerk, 2002. A Comparison of the Watershed Hydrology of Coastal Forested Wetlands and Mountainous Uplands in the Southern U.S. Journal of Hydrology 263:92-104.

Sun, G., S.G. McNulty, J. Lu, D.M. Amatya, Y. Liang, and R.K. Kolka, 2005. Regional Annual Water Yield From Forest Lands 
and Its Response to Potential Deforestation Across the Southeastern United States. Journal of Hydrology 308:258-268.

Sun, G. and Z. Zhang, 1989. Hydrologic Characteristics of Two Small Chinese fir Forest Watersheds in Southern China. Journal of Beijing Forestry University 3:25-31 [In Chinese].

Sun, P., S. Liu, H. Jiang, Y. Lü, J. Liu, Y. Lin, X. Liu, 2008. Hydrologic Effects of Linking NDVI Time Series in a Context of Climatic Variability in an Upstream Catchment of the Minjiang River. Journal of the American Water Resources Association (JAWRA) 44(5). DOI: 10.1111/j.1752-1688.2008.00246.x.

Swank, W.T., L.W. Swift, Jr., and J.E. Douglass, 1988. Streamflow Changes Associated With Forest Cutting, Species Conversion, and Natural Disturbances. In: Forest Hydrology and Ecology at Coweeta. Ecological Studies, Vol. 66. W.T. Swank, and D.A. Crossley, Jr. (Editors) Springer-Verlag, New York, pp. 297-312.

Swank, W.T., J.M. Vose, and K.J. Elliot, 2001. Long-Term Hydrologic and Water Quality Responses Following Commercial Clearcutting of Mixed Hardwoods on a Southern Appalachian Catchment. Forest Ecology and Management 143:163-178.

Szilagyi, J., 2000. Can a Vegetation Index Derived From Remote Sensing be Indicative of Areal Transpiration? Ecological Modeling 127:65-79.

Trimble, S.W., F.H. Weirich, and B.L. Hoag, 1987. Reforestation and Reduction of Water Yield on the Southeastern Piedmont Since Circa 1940. Water Resources Research 23:425-437.

Tucker, C.J., J.E. Pinzon, M.E. Brown, D. Slayback, E.W. Pak, R. Mahoney, E. Vermote, and N. El Saleous, 2005. An Extended AVHRR 8-km NDVI Data Set Compatible With MODIS and SPOT Vegetation NDVI Data. International Journal of Remote Sensing 26(20):4485-4498.

Vertessy, R.A., F. Watson, and S.K. O'Sullivan, 2001. Factors Determining Relations Between Stand Age and Catchment Water Balance in Mountain ash Forests. Forest Ecology and Management 143:13-26.

Vörösmarty, C.J., C.A. Federer, and A.L. Schloss, 1998. Potential Evaporation Functions Compared on US Watersheds: Possible Implications for Global-Scale Water Balance and Terrestrial Exosystem Modeling. Journal of Hydrology 207:147-169.

Wei, X., S. Liu, G.-Y. Zhou, and C. Wang, 2005. Hydrological Processes of key Chinese Forests. Hydrological Process 19(1):63-75.

Wei, X., G. Sun, S. Liu, H. Jiang, G. Zhou and L. Dai, 2008. The Forest-Streamflow Relationship in China: A 40-Year Retrospect. Journal of the American Water Resources Association, 44(5). DOI: $10.1111 /$ j.1752-1688.2008.00237.x.

Zhang, L., W.R. Dawes, and G.R. Walker, 2001. Response of Mean Annual Evapotranspiration to Vegetation Changes at Catchment Scale. Water Resources Research 37:701-708.

Zhang, Y., W.B. Rossow, A.A. Lacis, V. Oinas, and M.I. Mishchenko, 2004. Calculation of Radiative Fluxes From the Surface to top of Atmosphere Based on ISCCP and Other Global Data Sets: Refinements of the Radiative Transfer Model and the Input Data. Journal of Geophysical Research 109, D19105, doi: 10.1029/2003JD004457.

Zhang, Z., Y. Yang, X. Yu, K. He, G. Sun, et al., 1986. Forest Hydrology of Dakeng Watershed, Xiushui County, Jiangxi Province. Final Report, Beijing Forest University, Beijing. 150 pp. [In Chinese].

Zhou, G.-Y., J.D. Morris, J.H. Yan, Z.Y. Yu, and S.L. Peng, 2002. Hydrological Impacts of Reforestation With Eucalyptus and Indigenous Species: A Case Study in Southern China. Forest Ecology and Management 167:209-222. 